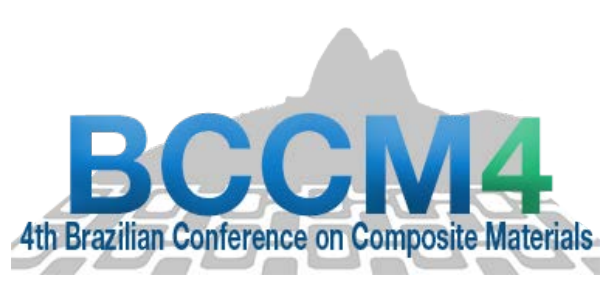

\title{
NUMERICAL AND EXPERIMENTAL ANALYSES ON THE CURING OF A THICK THERMOSETTING POLYMER MATRIX
}

\author{
$\underline{\text { Vivianne M. Bruère }} \stackrel{(1)}{ }$, Nadège Bouchonneau ${ }^{(1)}$ and Christian Jochum ${ }^{(2)}$ \\ (1) Department of Mechanical Engineering, Universidade Federal de Pernambuco, Brazil \\ (2) Service de Recherche en Mécanique des Structures Navales ENSTA Bretagne / IRDL-UMR \\ CNRS 6027, Brest, France.
}

https://doi.org/10.21452/bccm4.2018.13.01

\begin{abstract}
In the present work, the curing process of a thick thermosetting polymer matrix was investigated through experimental and Finite Element analyses. The study was carried out on COMSOL Multiphysics ${ }^{\circledR}$ software considering coupled thermal and chemistry phenomena involved in an epoxy's polymerization process. The curing parameters of two single-step and one two-step curing were investigated, denoting defective samples from the two first cases due to thermal degradation and a defect-free sample from the last one. Numerical results were in good agreement with experimental records, and thus reveal the potential of this COMSOL $®$ FE simulation.
\end{abstract}

Keywords: Curing; Finite Element; COMSOL Multiphysics®; Epoxy; Thermal degradation.

\section{INTRODUCTION}

The appearance of synthetic fiber-reinforced composites in late $19^{\text {th }}$ century, due to the development of resin polymerization and fiber fabrication processes, and their subsequent popularity increase after World War II, led to our current extensive composite industry. The growing mastery of fabrication processes and the development of designed materials with combinations of superior properties encourages the enlargement of the composites field, which can be seen in sectors such as aerospace, marine, construction and energy.

As a result, composite materials are currently the focus of several studies, aiming the achievement of a better control and optimization of the manufacturing process. Namely, fiberreinforced thermosetting polymer matrix composites show superior strength capabilities and are increasingly used in high performance applications to improve load capacity and reduce energy costs. The manufacturing of those composites, nevertheless, generally represents one of the main obstacles for their use. As the matrix undergoes a curing process, there is a chemical reaction, both 
thermoactivated and exothermic, as well as the coupling of several physics phenomena. The final properties of the material depend, therefore, on the curing.

Nonetheless, during curing internal stresses were already expressed in literature to be generated [1,2], which can induce quality defects such as bubbles, cracks and fiber waviness, depreciating the material's mechanical performance [3-7]. These defects become more relevant as the material's thickness increases since mass effects amplifie the exothermic factor of the curing. This is a central investigation point in thick laminates, whose use is constantly expanding in naval and offshore applications, as well as in components which withstand severe loads [8,9]. Another phenomenon associated with the cure of a thermosetting polymer matrix (TPM) is thermal degradation, triggered by internal overheat from the exothermic reaction. Particularly in thick laminates, temperature gradients are more intense, and lead to a high temperature profile and a more heterogeneous final material.

The knowledge and prediction of the material's internal state at the end of cure becomes essential and strategic for the industry, to identify the mechanical properties of the resulting product. Optimization studies of TPM curing cycle and manufacturing process have been carried out experimentally $[1,10,11]$, ensuring better mechanical properties to the composites. The downside of this knowledge is its approach of experimental origin and the materials being often intended for very specific use, which limit their applicability to a wider field. It is required, hence, to combine experimental analysis with another type of investigation.

For the laminate quality evaluation and determination of residual internal stresses, as well as solving of the implemented multiphysics couplings, the use of the Finite Element Method (FEM) is a very promising approach [8,9,12-16]. The execution and validation of $3 \mathrm{D}$ models of the material's curing process, considering chemical, thermal and mechanical coupled phenomena, is a key point to the elaboration of reliable predictive models. Studies with the use of this numerical tool are more and more present, and the constant evolution of FE software and computer speed increase are an additional impulse for its use in such analyses.

In this context, this work highlights the numerical modeling of curing of a thick thermosetting polymer matrix, more specifically, an epoxy resin. Epoxies are known to be widely used in highperformance applications for their excellent mechanical properties, dimensional stability and greater resistance to humidity. The purpose of this paper is, thus, to evaluate the curing cycle involving several physics, for a reliable and realistic prediction of the material's behavior in the composite's manufacturing process. COMSOL Multiphysics ${ }^{\circledR}$ software was used considering the coupled physics of thermal and chemistry as a means to develop fast, realistic and reliable predictive modeling approaches and simulations able to describe the epoxy behavior and to represent changes in material properties and gradients occurring during cure. In addition, a fully thermal-chemical-mechanical coupled model is in progress and is to be presented in future publications. Experimental tests were also performed to collaborate in the developing and validation of the models, for different curing processes.

\section{NUMERICAL METHODOLOGY}

As the curing consists of an exothermic reaction, the heat produced helps its activation, leading to a coupling of two physics: thermal and chemistry. A simple coupling of them was taken as an additional heat flow equivalent of that released by chemistry into the heat transfer equation, as the focus remains on the evolution of degree of cure and temperatures instead of how chemical species are reacting. Hence, the heat transfer equation used is: 


$$
\rho \mathrm{C}_{\mathrm{p}} \mathrm{dT} / \mathrm{dt}=\operatorname{div}\{\mathrm{k}[\operatorname{grad} \mathrm{T}]\}+\mathrm{q}+\rho \Delta \mathrm{H}_{\mathrm{r}} \mathrm{d} \alpha / \mathrm{dt}-\mathrm{T}\left\{(3 \kappa+2 \mu) \alpha_{\mathrm{T}}\right\} \operatorname{tr} \dot{\boldsymbol{\varepsilon}}
$$

where $\rho, \mathrm{C}_{\mathrm{p}}, \mathrm{k}$ and $\alpha_{\mathrm{T}}$ stand for the density, specific heat, thermal conductivity and coefficient of thermal expansion of the forming matrix, while $\mathrm{q}$ and $\Delta \mathrm{H}_{\mathrm{r}}$ are the heat imposed by the oven and the reaction's enthalpy, respectively, where $\rho \Delta \mathrm{H}_{\mathrm{r}} \mathrm{d} \alpha / \mathrm{dt}$ denotes the heat flow produced by the chemical reaction. Bulk and Shear moduli are given by $\kappa$ and $\mu$, the second-order strain tensor is $\dot{\boldsymbol{\varepsilon}}$ and $\mathrm{T}$ and $\alpha$ are the temperature and degree of cure. The last term of Equation (1) can be neglected for the heat induced from mechanics is low compared to the others.

\subsection{Cure kinetics}

The degree of cure was expressed by Kamal and Sourour's phenomenological model [17], considering both catalytic and auto-catalytic reaction effects. Diffusion phenomenon was added, since as curing evolves the polymerization reaction becomes more and more controlled by reactive species diffusion and more reduced in molecule mobility, slowing the reaction rate. Thus, Kamal and Sourour's model extended by Fournier et al. [18] was applied:

$$
\mathrm{d} \alpha / \mathrm{dt}=\left(\mathrm{K}_{1}+\mathrm{K}_{2} \alpha^{\mathrm{m}}\right)(1-\alpha)^{\mathrm{n}} \mathrm{f}_{\mathrm{d}}(\alpha)
$$

Exponent $\mathrm{m}$ is the order associated with the auto-catalytic reaction, and $\mathrm{n}$, with the catalytic one. Rate constants $\mathrm{K}_{1}$ and $\mathrm{K}_{2}$ from the catalytic and auto-catalytic processes, respectively, follow the Arrhenius Law, given in terms of pre-exponential constants $A_{1}$ and $A_{2}$, activation energies $E_{1}$ and $\mathrm{E}_{2}$, universal constant of perfect gases $\mathrm{R}$ and temperature $\mathrm{T}$ :

$$
\begin{aligned}
& K_{1}=A_{1} \exp \left[-E_{1} /(R T)\right] \\
& K_{2}=A_{2} \exp \left[-E_{2} /(R T)\right]
\end{aligned}
$$

Diffusion factor $\mathrm{f}_{\mathrm{d}}(\alpha)$ is expressed by

$$
\mathrm{f}_{\mathrm{d}}(\alpha)=-1+2 /\left\{1+\exp \left[\left(\alpha-\alpha_{\mathrm{f}}\right) / \mathrm{b}\right]\right\}
$$

where $\alpha_{\mathrm{f}}$ is the conversion that could be reached at the end of a corresponding isothermal cure performed at $\mathrm{T}$, and $\mathrm{b}$ is an empirical material diffusion constant. Rabearison et al. [19] defined cure kinetics parameters for a LY 556 epoxy system, with HY 917 hardener and DY 070 accelerator in a 100:90:2 mass ratio. The used parameters are presented in Tables 1 and 2.

Table 1: Cure Kinetics parameters

\begin{tabular}{ccccccc}
\hline $\mathrm{A}_{1}[1 / \mathrm{s}]$ & $\mathrm{A}_{2}[1 / \mathrm{s}]$ & $\mathrm{E}_{1}[\mathrm{~kJ} / \mathrm{mol}]$ & $\mathrm{E}_{2}[\mathrm{~kJ} / \mathrm{mol}]$ & $\mathrm{m}$ & $\mathrm{n}$ & $\mathrm{R}[\mathrm{J} /(\mathrm{mol} \mathrm{K})]$ \\
\hline 1339879.17 & 21042820.69 & 69.14 & 72.62 & 1 & 2 & 8.314 \\
\hline
\end{tabular}

Table 2: Diffusion factor parameters

$\alpha_{\mathrm{f}}: 4.0646 * 10^{-3} \mathrm{~T}[\mathrm{~K}]-8.2434 * 10^{-1} \quad$ b: $7.1588^{*} 10^{-4} \mathrm{~T}[\mathrm{~K}]-2.2816^{*} 10^{-1}$

Parameters $\alpha_{\mathrm{f}}$ and b were defined for temperature ranges between $360 \mathrm{~K}$ and $420 \mathrm{~K}$. As the final degree of cure cannot exceed $100 \%$, physically speaking, for temperatures above $448.8 \mathrm{~K} \alpha_{\mathrm{f}}$ remains constant. Limitation of b consists of not achieving zero - indeterminacy in $\mathrm{f}_{d}(\alpha)$ 's denominator -, and so this parameter remains constant at temperatures below $319 \mathrm{~K}$. 


\subsection{Glass transition temperature}

As epoxy undergoes structural and phase changes - liquid to rubbery solid, and then to glassy solid -, which directly affects material's properties, the glass transition temperature, $T_{g}$, had to be properly described by DiBenedetto's equation [20], the most common model:

$$
\mathrm{T}_{\mathrm{g}}=\mathrm{T}_{\mathrm{g} 0}+\left[\lambda \alpha\left(\mathrm{T}_{\mathrm{g} \infty}-\mathrm{T}_{\mathrm{g} 0}\right)\right] /[1-(1-\lambda) \alpha]
$$

where $\mathrm{T}_{\mathrm{g} 0}$ and $\mathrm{T}_{\mathrm{g} \infty}$ are the glass transition temperatures for uncured and fully cured resin, and $\lambda$ is an adjustable parameter, assuming the values $236 \mathrm{~K}, 409 \mathrm{~K}$ and 0.57, respectively [21].

\subsection{Epoxy's material properties}

The epoxy system's density has a small variation throughout the curing process - less than $10 \%$. Thus, its density was taken as constant and equal to $1170.6 \mathrm{~kg} / \mathrm{m}^{3}$. The material's specific heat capacity, thermal conductivity and coefficient of thermal expansion vary according to the Rules of Mixtures [9] as $\mathrm{C}_{\mathrm{p}}(\alpha, \mathrm{T})=(1-\alpha) \mathrm{C}_{\mathrm{p}}(0, \mathrm{~T})+\alpha \mathrm{C}_{\mathrm{p}}(1, \mathrm{~T}), \mathrm{k}(\alpha, \mathrm{T})=(1-\alpha) \mathrm{k}(0)+\alpha \mathrm{k}(1, \mathrm{~T})$ and $\alpha_{\mathrm{T}}(\alpha, \mathrm{T})$ $=(1-\alpha) \alpha_{\mathrm{T}}(0, \mathrm{~T})+\alpha \alpha_{\mathrm{T}}(1, \mathrm{~T})$, where:

$$
\begin{aligned}
& \mathrm{C}_{\mathrm{p}}(0, \mathrm{~T})=1.8500+0.002625 * \mathrm{~T}\left[{ }^{\circ} \mathrm{C}\right]\left[\mathrm{J} /\left(\mathrm{g}{ }^{\circ} \mathrm{C}\right)\right] \\
& \mathrm{C}_{\mathrm{p}}(1, \mathrm{~T})=1.3125+0.004437 * \mathrm{~T}\left[{ }^{\circ} \mathrm{C}\right], \mathrm{T}<\mathrm{T}_{\mathrm{g} \infty} \text { or } \mathrm{C}_{\mathrm{p}}(1, \mathrm{~T})=\mathrm{C}_{\mathrm{p}}(0, \mathrm{~T}), \mathrm{T} \geq \mathrm{T}_{\mathrm{g} \infty}[\mathrm{J} /(\mathrm{g} \\
& \left.\left.{ }^{\circ} \mathrm{C}\right)\right] \\
& \mathrm{k}(0)=0.188 \text { and } \mathrm{k}(1, \mathrm{~T})=-2.72710^{-4} * \mathrm{~T}\left[{ }^{\circ} \mathrm{C}\right]+3555.529 * 10^{-4}\left[\mathrm{~W} /\left(\mathrm{m}^{\circ} \mathrm{C}\right)\right] \\
& \alpha_{\mathrm{T}}(0, \mathrm{~T})=5 * 10^{-4}\left[1 /{ }^{\circ} \mathrm{C}\right] \\
& \alpha_{\mathrm{T}}(1, \mathrm{~T})=450 * 10^{-6}, \mathrm{~T}<\mathrm{T}_{\mathrm{g}} \text { or } \alpha_{\mathrm{T}}(1, \mathrm{~T})=450^{\circ} 10^{-6}+4.1 * 10^{-6 *}\left(\mathrm{~T}-\mathrm{T}_{\mathrm{g}}\right), \mathrm{T} \geq \mathrm{T}_{\mathrm{g}}[1 / \\
& \left.{ }^{\circ} \mathrm{C}\right]
\end{aligned}
$$

The epoxy system is inserted into a steel mold, with a density of $7800 \mathrm{~kg} / \mathrm{m}^{3}$, thermal conductivity and specific heat capacity of $24 \mathrm{~W} /(\mathrm{m} \mathrm{K})$ and $460 \mathrm{~J} /(\mathrm{kg} \mathrm{K})$, respectively, at $293 \mathrm{~K}$, and of $29 \mathrm{~W} /(\mathrm{m} \mathrm{K})$ and $540 \mathrm{~J} /(\mathrm{kg} \mathrm{K})$ at $773 \mathrm{~K}$.

\subsection{Heat flow from chemical reaction and from the oven}

This is represented by term $\rho \Delta \mathrm{H}_{\mathrm{r}} \mathrm{d} \alpha / \mathrm{dt}$ in Equation (1). From previous DSC experiments [19], we could express this term as:

$$
\begin{aligned}
& \rho \mathrm{H}_{U} \mathrm{~d} \alpha / \mathrm{dt}=1170600 * 330 * \mathrm{~d} \alpha / \mathrm{dt}, \mathrm{T}<\mathrm{T}_{\mathrm{g}} \\
& \rho \mathrm{H}_{U}\left(\mathrm{H}_{\mathrm{T}} / \mathrm{H}_{\mathrm{U}}\right) \mathrm{d} \alpha / \mathrm{dt}=1170600 * 330 *(0.00243 * \mathrm{~T}[\mathrm{~K}]-0.158) * \mathrm{~d} \alpha / \mathrm{dt}, \mathrm{T} \geq \mathrm{T}_{\mathrm{g}}
\end{aligned}
$$

$\mathrm{H}_{\mathrm{T}}$ and $\mathrm{H}_{\mathrm{U}}$ are the enthalpy of the reaction at a given temperature and the total enthalpy for the complete reaction, respectively, where $\mathrm{H}_{U}$ was found to be $355 \pm 25 \mathrm{~J} / \mathrm{g}$ [19]. As for the heat imposed by the oven, only the convection was considered, since the dimensions of the oven relative to the epoxy sample were considerably larger. Therefore,

$$
\mathrm{q}=\mathrm{h}\left(\mathrm{T}-\mathrm{T}_{\mathrm{e}}\right)
$$

Coefficient of convection $\mathrm{h}$ was previously calculated [22], and $\mathrm{T}_{\mathrm{e}}$ is the oven temperature.

\subsection{COMSOL Multiphysics ${ }^{\circledR}$ Implementation}

In the software, all varying parameters were added as interpolation, piecewise or analytic functions. The program allowed an easy implementation with simple logical expressions, 
exempting the need of an associated programming language. Cure kinetics equation was solved inside COMSOL ${ }^{\circledR}[23]$ itself with Domain ODEs DAEs module; Heat Transfer module governed the thermo-chemical coupling. The investigated geometry consisted of a $32 \mathrm{~mm}$-diameter and 60 mm-height of the epoxy inside a steel mold of overall $45 \mathrm{~mm}$-diameter and $65 \mathrm{~mm}$-effective height. The 2D-axisymmetric geometry mesh was had quadrilateral (for the epoxy) and coarser triangular elements (for the mold), with a total of 645 elements.

\section{EXPERIMENTAL METHODOLOGY}

Curing at three different temperatures were carried out, all of them with heating and cooling rates of $3^{\circ} \mathrm{C} / \mathrm{min}$, based on manufacturing practices. The investigated temperatures were: singlestep curing at $140^{\circ} \mathrm{C}$ with a $2 \mathrm{~h}$ isothermal plateau; single step-curing at $110^{\circ} \mathrm{C}$, also with a $2 \mathrm{~h}$ plateau; and the manufacturer's recommendation - a two-step curing at $80^{\circ} \mathrm{C}$ for $4 \mathrm{~h}$, followed by a $4 \mathrm{~h}$ plateau at $120^{\circ} \mathrm{C}$. Thermocouples registered the temperatures on the mold's wall and inside the oven. For the $140^{\circ} \mathrm{C}$ case, it was also possible to record the temperature in the epoxy sample's center. Samples were prepared respecting the mass ratio of 100:90:2 for a LY 556 epoxy system, with HY 917 hardener and DY 070 accelerator. As the resin preparation led to the appearance of bubbles, the samples were placed before curing in a vacuum chamber to remove these bubbles and reduce sources of defects.

\section{RESULTS ANALYSIS}

The resulting samples (Figure 1) for the single-step curing processes evidenced the presence of cracks. Although all the bubbles might not be removed before curing, a likely motive is thermal degradation: high temperatures achieved during curing provoke the phenomenon, leading to loss of mass, followed by the formation of gases and bubbles, which increases the epoxy's internal pressure and, consequently, induces cracks in the material.

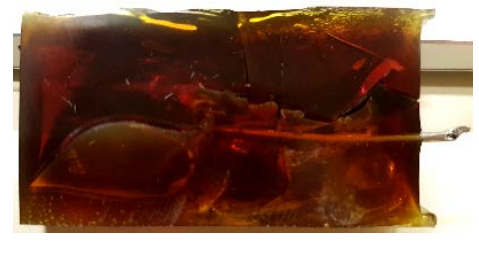

(a)

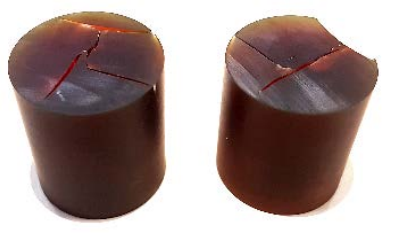

(b)
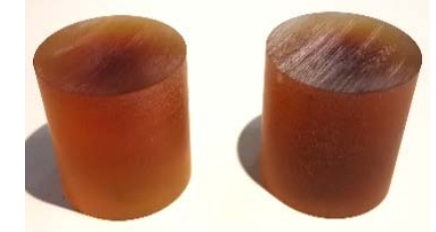

(c)

Figure 1: Epoxy samples for the (a) $140^{\circ} \mathrm{C}$ and (b) $110^{\circ} \mathrm{C}$ single-step and (c) two-step curing.

The color gradients - darker coloration in the center, better detected at Figure 1c - indicate the degree of cure gradients and its higher values inside the geometry. This is a reflex of the curing temperature - which the greater it is, the higher the temperature peaks due to difficulty in heat getting transferred out of the resin. The two-step curing, based on manufacturer's recommendation, showed no signs of defects, proving to be a safe procedure.

Numerical simulations from COMSOL ${ }^{\circledR}$ and experimental data provided similar results. For the $140^{\circ} \mathrm{C}$ curing (Figure 2), recorded temperatures on the center (Center Exp from the experiment and $\mathrm{T} 1$ from simulation) agree on the peak from the intense exothermic reaction. 


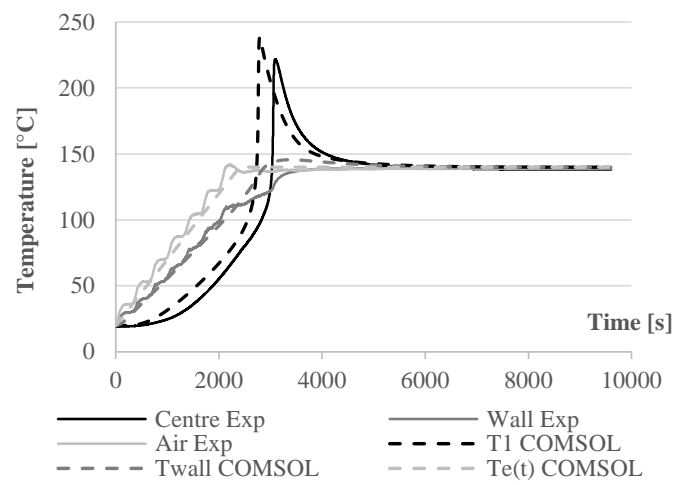

Figure 2: Temperature evolution Experiment x Simulation: $140^{\circ} \mathrm{C}$.

The wall temperatures, however, distant themselves a little at the temperature peak duration in the epoxy's center. A possible reason could be the coefficient of convection h, added to the model from previous works. The peak in center's temperature rises the wall's as well, probably leading to changes in h. These dissimilarities also occur for the $110^{\circ} \mathrm{C}$ and the two-step curing (Figure 3). This denotes improvements to be made in this aspect of the model.

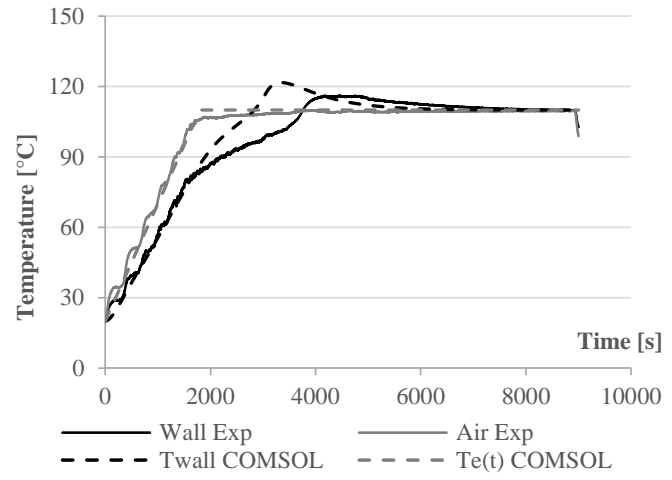

(a)

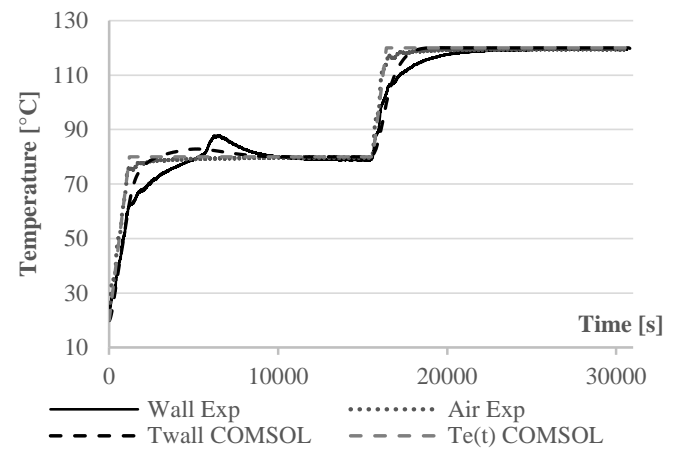

(b)

Figure 3: Temperature evolution Experiment x Simulation: (a) $110^{\circ} \mathrm{C}$ and (b) two-step curing.

The evolutions of degree of cure and temperatures at the center (maximum values; index 1) and the outer edge (minimum values; index 4) are presented for the three simulated cases: single-step curing at $140^{\circ} \mathrm{C}$ and $110^{\circ} \mathrm{C}$ and the two-step curing at $80^{\circ} \mathrm{C}+120^{\circ} \mathrm{C}$ (Figure 4). A higher curing temperature, as expected, led to higher degree of cure rates as the curing agent is concentrated on the faster crosslinking reactions, resulting in a more heterogeneous material. Peak temperatures were found to be $238^{\circ} \mathrm{C}\left(140^{\circ} \mathrm{C}\right.$ curing $), 199^{\circ} \mathrm{C}\left(110^{\circ} \mathrm{C}\right.$ curing $)$ and $121^{\circ} \mathrm{C}\left(80^{\circ} \mathrm{C}+120^{\circ} \mathrm{C}\right.$ curing $)$. As thermal degradation starts around $160^{\circ} \mathrm{C}$ and becomes more intense after $200^{\circ} \mathrm{C}$ for the LY 556 epoxy system, we detect the degradation phenomenon for the single-step cases, which indeed provided cracked samples. The manufacturer's recommendation $\left(80^{\circ} \mathrm{C}+120^{\circ} \mathrm{C}\right.$ curing), on the other hand, proved to be appropriate for giving a more homogeneous material, and exempting it from thermal degradation, especially for the studied geometry, in which mass effects occur from its larger thickness. Nevertheless, the final degree of cure reached is below $80 \%$ and highlights the need of a third curing stage (post-cure) to achieve a higher level of degree of conversion. 
$4^{\text {th }}$ Brazilian Conference on Composite Materials. Rio de Janeiro, July $22^{\text {nd }}-25^{\text {th }}, 2018$

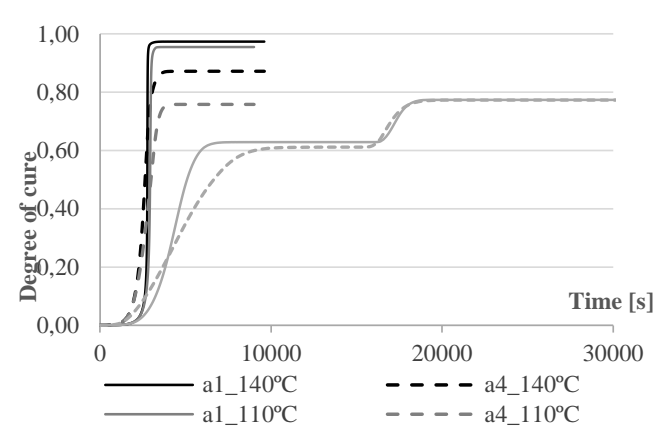

(a)

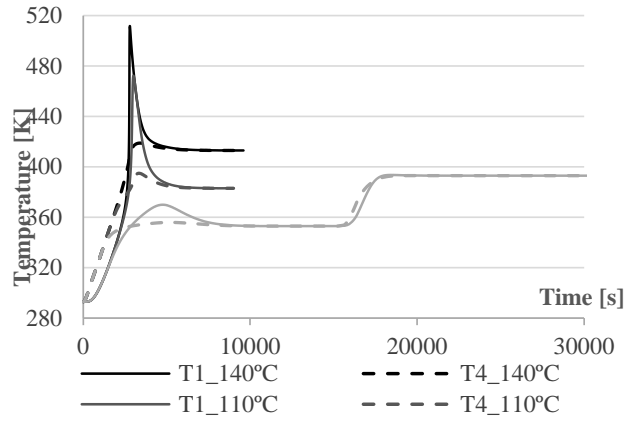

(b)

Figure 4: Maximum [index 1] and minimum [index 4] (a) degree of cure [a] and (b) temperature $[\mathrm{T}]$ evolutions for the investigated curing processes.

\section{CONCLUSIONS}

A finite element modeling of the curing process of an epoxy resin matrix was presented. The chosen software, COMSOL Multiphysics ${ }^{\circledR}$, provided coupled thermo-chemical predictions of curing parameters in accordance to experiments, with an implementation using the own program resources. Results reveal the importance of curing temperature on the final material in terms of homogeneity and of it being subjected to thermal degradation, which may interfere on its quality. For thick epoxies, mass effects strongly influence the material's final state, since lower heat diffusion to the outside causes the appearance of higher temperatures and gradients and, hence, giving rise to thermal degradation, impairing the product. Improvements are yet to be accomplished for oven convection and the fully coupled thermo-chemical-mechanical model, already in investigation. Thereby, this works highlights the importance of knowledge on the curing of an epoxy resin, in which the achievement of good final properties and material quality derives from control and optimization of manufacturing processes, and exposes the great potential of the FEM for reliable curing quality predictions.

\section{ACKNOWLEDGEMENTS}

The authors would like to thank ENSTA Bretagne, for providing the infrastructure to perform the experimental tests. The authors also wish to thank CNPq (MCTI/CNPq/Universal 14/2014 Process number: 460973/2014-2) for the financial support.

\section{REFERENCES}

[1] Jochum, Ch., Grandidier, J.-C., Smaali, M., 'Experimental study of long T300 carbon fibre undulations during the curing of LY556 epoxy resin’, Compos. Sci. Technol. 67 (2007) 26332642.

[2] Jochum, Ch., Grandidier, J-C., Smaali, M.A.,'Proposal for a long-fibre microbuckling scenario during the cure of a thermosetting matrix'. Compos. Part A 39 (2008) 19-28.

[3] Adams, D.O., Hyert, M.W., 'Effects of layer waviness on the compression fatigue performance of thermoplastic composite laminates'. Fatigue 16 (1994) 385-392.

[4] Hsiao, H.M., Daniel, I.M, 'Effect of fiber waviness on stiffness and strength reduction of unidirectional composites under compressive loading'. Compos. Sci. Technol. 56 (1996) 581-593.

[5] Drapier, S., Grandidier, J-C., Potier-Ferry, M.,'A non-linear numerical approach to the analysis of microbuckling'. Compos. Sci. Technol. 58 (1998) 785-790. 
$4^{\text {th }}$ Brazilian Conference on Composite Materials. Rio de Janeiro, July $22^{\text {nd }}-25^{\text {th }}, 2018$

[6] Stecenko, T., Piggott, M.R., 'Fiber waviness and other mesostructures in filament wound materials'. J. Reinf. Plast. Compos. 16 (1997) 1659-1674.

[7] Drapier, S., Grandidier, J-C., Potier-Ferry, M., 'A structural approach of plastic microbuckling in long fibre composites: comparison with theoretical and experimental results'. Int. J. Solids Struct. 38 (2001) 3877-3904.

[8] Balvers, J.M., Bersee, H.E.N., Beukers, A., Jansen, K.M.B, 'Determination of cure dependent properties for curing simulation of thick-walled composites'. 49th AIAA/ASME/ASCE/AHS Structures, Structural Dynamics, and Materials Conference. Schaumburg, April, 2008 (American Institute of Aeronautics and Astronautics, 2008-2035) 1-15.

[9] Rabearison, N., Jochum, Ch., Grandidier, J-C. 'A FEM coupling model for properties prediction during the curing of an epoxy matrix'. Comput. Mater. Sci. 45 (2009) 715-724.

[10]Ruiz, E., Trochu, F., 'Multi-criteria thermal optimization in liquid composite molding to reduce processing stresses and cycle time’. Compos. Part A 37 (2006) 913-924.

[11]Grandidier J.-C., Casari P., Jochum Ch., 'A compressive failure criterion for long fibre laminates based on laminate thickness effect and stacking sequence'. Proceedings of the ICCS 2016 International Conference on Computational Science. San Diego, June, 2016.

[12]Lord, S., Stringer, L.G., 'A modelling approach for predicting residual stresses and distortions in polymer composites'. 17th International Conference on Composite Materials. Edinburgh, July, 2009.

[13]Zhang, J., Xu, Y.C., Huang, P., 'Effect of the cure cycle on curing process and hardness for epoxy resin'. Express Polym. Lett. 3 (2009) 534-541.

[14]Msallem, Y.A., Jacquemin, F., Poitou, A., 'Residual stresses formation during the manufacturing process of epoxy matrix composites: resin yield stress and anisotropic chemical shrinkage'. Int. J. Mater. Form. 3 (2010) 1363-1372.

[15]Shevtsov, S.N., Axenov, V.N., Alekseeva, O.D., Vetrova, T.I., 'Cure kinetics of epoxy resin and distributed thermal control of polymeric composite structures moulding. $3^{\text {rd }}$ International Conference Physics and Control. Potsdam, September, 2007.

[16]Jochum, Ch., Arrigoni, M., Boustie, M., Grandidier, J.-C., 'A cut-off fracture approach for residual stress estimation in thick epoxies'. Materwiss. Werksttech. 47 (5-6) (2016) 530-538.

[17]Kamal, M.R., 'Thermoset characterization for moldability analysis'. Polym. Eng. Sci. 14 (1974) 231-239.

[18]Fournier, J., Williams, G., Duch, C., Aldridge, G.A., 'Changes in molecular dynamics during bulk polymerization of an epoxyde-amine system as studied by dielectric relaxation spectroscopy'. Macromolecules 29 (1996) 7097-7107.

[19]Rabearison, N., Jochum, Ch., Grandidier, J.-C., 'A cure kinetics, diffusion controlled and temperature dependent, identification of the Araldite LY556 epoxy’. J. Mater. Sci. 46 (2011) 787796.

[20]DiBenedetto, A.T., 'Prediction of the glass transition temperature of polymers: a model based on the principle of corresponding states'.J. Polym. Sci., Part B: Polym. Phys. 25 (1987) 1949-1969.

[21]Rabearison, N., Jochum, Ch., Grandidier, J.-C., 'A finite element coupling model for internal stress prediction during the curing of thick epoxy composites'. International Conference on Flow Processes in Composite Materials. Montreal, July, 2008.

[22]Rabearison, N. 'Elaboration d'un outil numérique dédié à la simulation du procédé de fabrication des matériaux composites à résine thermodurcissable - prédiction des contraintes internes'. Université de Bretagne Occidentale, Brest, 2009.

[23]COMSOL Multiphysics® v. 5.1. www.comsol.com. COMSOL AB, Stockholm, Sweden. 